klein und geschlängelt, wie die Temporalis; die Wandungen der Arterien erschienen hart.

Die Frau verstand sich nicht zu einem operativen Eingriff und es mußte eine symptomatische Behandlung eingeleitet werden: Opiate, Jodkali wurden innerlich gegeben, daneben Kompression des Aneurysma mit einem Schrotbeutel. Die Frau konnte nur auf dem Bauche liegen. Von Tag zu Tag steigerten sich die Beschwerden, und mit diesen hielt die weitere Ausbreitung der Geschwulst gleichen Schritt. Sie stieß bald an den fühlbaren Kreuzbeinrand an und dehnte sich nach oben und unten hin weiter aus, während nach dem Trochanter hin keine Zunahme zu beobachten war. Sie hatte die Größe eines Kindskopfes und schien aus dem Gesäß emporzuquellen. Die Art des Wachstums nach oben, nach unten und nach innen ließ mich mit Bestimmtheit ein Aneurysma der Art. glutaea inferior annehmen. Bei der großen Schwierigkeit, auf diese Arterie einzugehen und das Aneurysma zu spalten, entschlo $B$ ich mich zur Unterbindung der Art. hypogastrica dextra. Sie wurde am 12. November derart ausgefuhrt, daB ich nach Auffindung der Arterie diese gewissermaßen auf dem Unterbindungsfaden reiten ließ, und den Faden heraufführend bis zur Abgangsstelle der Arterie und herunterführend bis zum Abgang eines Astes, unterband ich so, dal ich in der Mitte zwischen diesen beiden Punkten zuknotete. Ich glaube, daß bei Tnterbindung größerer Gefaße der Chirurg stets darauf sehen muß, daß die Unterbindungsstelle so weit vom Abgang eines Gefälies sowohl nach oben als auch nach unten entfernt ist, daß ein mechanisches Hindernis der Heilung der Unterbindungsstelle nicht statthaben kann: sie muß von der zentralen Teilung wenigstens in der doppelten Länge des Querdurchmessers der zu unterbindenden Arterie entfernt sein. So werden die so häufigen Nachblutungen vermieden werden und die Erfolge der Unterbindungen der größeren Gefäße viel zahlreicher sein als bisher.

Beim Eingehen auf die Hypogastrica und beim Abtasten von der Iliaca war die Differenz der Gefäßstärken sehr auffallig: sie schienen ihre Lumina vertauscht zu haben, und die Hypogastrica machte dem tastenden Finger den Eindruck, als ob sie noch einmal so stark sei als die Iliaca.

Die Pulsation hörte mit der Unterbindung auf, der Tumor selbst wurde unmittelbar fester und scheinbar größer. Gegen Abend ließ sich schon eine beträchtliche Abnahme nachweisen. Der $W^{\top}$ undverlauf war bis auf die Bildung eines kleinen Abscesses in der Tiefe ein glatter, und die Frau konnte am 24. Dezember 1901 als geheilt entlassen werden. Das Anenrysma war immer mehr gescbrumpft und neben dem Trochanter in der Tiefe eigroß zu fühlen es pulsierte garnicht mehr und machte garkeine Beschwerden.

In diesem Falle ist die Einwirkung der Unterbindung des Aneurysmas auf den allgemeinen Kreislauf erwähnenswert. Nach der Operation traten Schwellungen der Unterschenkel ein, der Puls wurde voller und machte einen weniger geschlängelten Eindruck. Die Frau klagte sehr über Schwäche und Herzklopfen. Das Anasarca der Haut der Unterextremitäten war bei ihrer Entiassung geringer, aber noch nicht ganz fehlend, und es hat beinahe ein halbes Jahr gedauert, bis sie sich vollkommen erholte. Im Juni 1902 sah ich sie wieder. Sie sah sehr wohl aus, und ich fand neben dem Trochanter nur noch ein kleines, bohnengroßes Knötchen in der Tiefe.

Die Frau ist gesund geblieben und trăgt heute noch die schwersten Trachten Holz aus dem Walde und soll nach den allerneuesten Nachrichten des dortigen Kollegen voll und blühend sein.

Für die Entstehung dieses Aneurysmas ist doch wohl der Fall

Aus dem Landkrankenhaus in Hersfeld.

\title{
Unterbindung der Arteria hypogastrica dextra wegen Aneurysma der Arteria glutaea inferior.
}

Von Direktor Dr. Carl Israel.

Frau Tagelöhner Gramm aus der Năhe von Oberaula wurde am 20. Oktober 1901 ins hiesige Landkrankenhaus aufgenommen. Sie war 56 Jahre alt, gab an, schon seit Monaten an ischiadischen Schmerzen zu leiden und jetzt eine große Geschwulst im rechten Hinterbacken zu haben. Im Herbste des Jahres 1900 sei sie auch einmal auf diese Partie gefallen, doch schien sie diesem Falle keine besondere Bedeutung beizumessen. Bei der Besichtigung fand sich eine pulsierende, an den erhabensten Stellen fast unter der Haut liegende, sonst mehr tiefe Geschwulst von enormer Ausdehnung, die beim Abtasten nach dem Trochanter sehr dicke Oberlage zu haben schien und mit diesem gewissermaBen abschloB. Die Frau war sehr mager, sah elend aus, hatte keinen Appetit; der Puls war verantwortlich zu machen, den sie einmal beim Holzschleppen nach hinten und rechts erlitten haben will. Meine Ansicht habe ich bei dem Verlauf der Erholung nach der Unterbindung sehr ändern müssen: während ich zuerst nach dem Finden der Hypogastricaverdickung, der scheinbaren Atherose der Arterien und nach dem kleinen Pulse diese Erscheinungen als Erkrankungen der GefäBe verantwortlich für das Aneurysma machte, fasse ich jetzt nach der vollständigen Erholung der Patientin das Aneurysma nicht nur als eine schwere lokale Erkrankung auf, sondern sage auch, daB die Einwirkung solcher enormen Blutbeutel auf den gesamten Kreislauf und das Befinden des Organismus von beträchtlichem Nachteil und daß selbst bei gutem Verlauf die Erholung des Kreislaufs eine nur langsame ist; daB das Fehlen des Blutes, welches sich in dem kindskopfgroßen Beutel ansammelt, den Puls klein macht und dadurch die Adern fester und geschlängelter erscheinen läßt und daß das Zurücktreten der Blutmengen in den Kreislauf eine Ueberlastung des Zirkulationsapparates bedingt und die ödematösen Schwellungen hervorruft. 